\title{
Assessing Safe and Independent Living in Vulnerable Older Adults: Perspectives of Professionals Who Conduct Home Assessments
}

\author{
Aanand D. Naik, MD, Mark E. Kunik, MD, MPH, Kristin R. Cassidy, BS, \\ Jeethy Nair, MD, and John Coverdale, MD, MEd
}

Objectives: The objectives of this study were to describe social services and health professionals' perceptions of vulnerability among older adults living in the community and to elicit how these professionals screen vulnerability in community and in-home settings.

Methods: Focus group sessions were conducted and analyzed using standardized methods of qualitative analysis. Participants included social services and health professionals $(n=45)$ who routinely encounter vulnerable older adults.

Results: Four themes characterized vulnerability: the inability to perform activities of daily living, lack of social support, sociodemographic factors, and neuropsychiatric conditions. When screening older adults, participants reported evaluating basic cognitive abilities, decision-making processes, and the capacity to adequately plan and safely perform everyday tasks. Participants stated that screening is best performed by an interdisciplinary team in the home setting and preferably on more than one occasion.

Conclusions: Social services and health professionals in this study described routinely screening for vulnerability in community-living older adults using a multidomain approach. These professionals endorse the use of assessments that screen an older adult's cognitive and functional capacities for safe and independent living. Further research is needed that integrates routine screening for vulnerability by community social services professionals with the assessments and interventions conducted by primary care physicians. (J Am Board Fam Med 2010;23:614-621.)

Keywords: Vulnerable Populations, Independent Living, Aging, Behavioral Sciences, Decision Making, Geriatrics, Qualitative Research

Older adults represent a large and growing proportion of the typical primary care provider's practice. ${ }^{1}$ Older adults report that living safely and independently in their own home is a principal health goal. ${ }^{2}$ Disability, aging, and illness can adversely affect

This article was externally peer reviewed.

Submitted 31 March 2009; revised 12 March 2010; accepted 12 March 2010.

From the Houston Health Services Research and Development Center of Excellence (ADN, MEK, KRC, JN) and the Veterans Affairs South Central Mental Illness Research, Education and Clinical Center (ADN, MEK), Michael E. DeBakey Veterans Affairs Medical Center; the Alkek Department of Medicine (ADN, MEK) and the Menninger Department of Psychiatry and Behavioral Medicine (MEK, JC), Baylor College of Medicine; and the Harris County Hospital District (ADN, JC), Houston, TX.

Funding: This study was supported by a bioethics project grant from the Greenwall Foundation $(\mathrm{ADN})$ and with resources and the use of facilities at Houston Veterans Affairs Health Services Research and Development Center of Excellence (HFP90-020). Dr. Naik is also supported by a K23 grant from the National Institute on Aging (5K23AG027144) and a the ability of an older adult to live independently by increasing one's vulnerability to health and safety risks within the home. ${ }^{3}$ Vulnerability is the failure to engage in acts of self care that adequately regulate safe and independent living, or to take actions

Doris Duke Charitable Foundation Clinical Scientist Development Award. The views expressed herein are those of the authors and do not necessarily reflect those of the Department of Veterans Affairs or Baylor College of Medicine. None of the funding agencies played a role in the design and conduct of the study, analysis and interpretation of the data, or the preparation and approval of the manuscript.

Conflict of interest: none declared.

Corresponding author: Aanand D. Naik, MD, Houston Center for Quality of Care and Utilization Studies, Michael E. DeBakey VAMC (152), 2002 Holcombe, Houston, TX 77030 (E-mail: anaik@bcm.edu).

See Related Commentary on Page 564. 
to prevent conditions or situations that adversely affect personal health and safety. ${ }^{3-6}$ Vulnerable older adults may display poor personal care and nutrition, have difficulty managing basic medications and personal finances, or live in unsafe environments regardless of physical appearance or behavior. ${ }^{3,7}$ Furthermore, vulnerable older adults are at risk for neglect, exploitation, and numerous safety hazards, as well as functional impairment, medical morbidity, and death. ${ }^{8-11}$ Thus, a common denominator among vulnerable, community-living older adults may be the diminished ability to perform personal care tasks and protect themselves.

Primary care interventions that target vulnerable community-living and homebound older adults have demonstrated effectiveness at reducing mortality and placement in long-term care. ${ }^{12,13}$ The issue of assessing vulnerability, therefore, is of particular importance to primary care physicians. However, the clues to recognizing vulnerability are often not readily apparent during routine primary care visits. ${ }^{3,14}$ Assessments done in outpatient settings may lead to erroneous assumptions about an older adult's vulnerability. ${ }^{15}$ Furthermore, hospital staff and outpatient clinicians rarely have the opportunity to observe patients' home environments to ascertain their ability to live safely and independently. ${ }^{16}$ One goal of assessing vulnerability is to identify and implement interventions that prevent further impairments and harms to allow older adults to continue to live at home. Assessments that are conducted in patients' homes are more effective at tailoring interventions to reduce vulnerability. ${ }^{13}$

Financial and geographic barriers are important impediments to home-based primary care services in most settings. In one study, more than half of primary care providers reported that they conducted home visits; however, only $8 \%$ perform more than 2 visits per month. ${ }^{17}$ Physicians who report that they perform routine home visits tend to be older and live in rural areas. ${ }^{17}$ Family medicine residency programs provide specific training for geriatric assessment, including home-based primary care, but with variable emphasis on assessing vulnerability. ${ }^{1,18}$

Primary care physicians continue to endorse the importance of home-based assessments of vulnerability as part of their scope of practice. ${ }^{19}$ To address this gap, primary care physicians sometimes rely on the services of other clinical and social services professionals. ${ }^{17}$ Primary care physicians cannot rely on a standardized assessment battery for vulnerability because of the heterogeneity of assessment tools across clinical and social services disciplines. ${ }^{3,20}$ In addition, their recommendations for interventions are limited by a lack of consensus across disciplines of what constitutes vulnerability for safe and independent living among older adults. $^{3,21}$

\section{Methods \\ Study Design and Sample}

The overall aim of the current study was to address these critical issues from the perspective of social services and health professionals who often conduct assessments in the homes of community-living older adults. First, participants were asked their perceptions of the dimensions of vulnerability among older adults living in the community. Second, participants were asked to identify how they go about screening for vulnerability in communitybased and in-home settings. From these results and the available literature, a framework can be proposed for integrating community-based screening methods with more comprehensive strategies for clinical assessment and intervention primarily directed by primary care physicians caring for vulnerable older adults.

This qualitative study consisted of 5 focus groups $(n=45)$ held between January and April 2007. Participants were purposively sampled to obtain perspectives and experiences from a range of clinical and social services professionals. ${ }^{22} \mathrm{We}$ chose 5 sites from which to gather our sample: a community-based social services organization $(\mathrm{n}=$ 6); a multidisciplinary geriatrics team from a publicly funded community hospital $(\mathrm{n}=9)$; an academic geriatrics faculty from a medical school $(\mathrm{n}=$ 8); case managers with State Adult Protective Services $(\mathrm{n}=10)$; and an interdisciplinary provider group of case managers, psychologists, lawyers, and social workers affiliated with a county Guardianship program $(\mathrm{n}=12)$. A contact from each group identified potential participants. Overall the focus groups provided a heterogeneous sample of professional disciplines and organizational missions. All participants had worked with older adults or had experience with addressing issues related to the study questions.

We introduced the project at each focus group with a statement of purpose. We explained that the 
purpose of the project arose from a need for a tool to screen vulnerable older adults' capacity for selfcare and self-protection. Once the study was explained to potential participants, a member of the research team obtained consent and demographic data. Participants were given a nominal gift certificate for their time and participation. The Institutional Review Board at Baylor College of Medicine approved this study.

\section{Data Collection and Analysis}

Semistructured interview guides were used for all groups. One trained member of the research team, who was not involved in data analysis, moderated all focus group sessions. Participants were asked to discuss the following 2 main areas: (1) When you evaluate someone in his or her home, what are the indicators or red flags that someone is vulnerable to a significant health or safety hazard, or susceptible to neglect and exploitation? (2) How do you typically screen for vulnerability in your clients? Are there particular functional and cognitive domains that you assess? How could a standardized tool assist you with that process?

Focus groups lasted approximately 1 hour and were audio taped. After transcription, 2 of the investigators $(\mathrm{JC}, \mathrm{JN}$ ) repeated critical readings of the 5 transcripts until they could not identify any additional new codes. This analytic process involved line-by-line scrutiny of text to identify and sort segments of data. ${ }^{23}$ A code key and structured dataabstraction instrument was developed from these repeated preliminary readings of all the materials, which was then applied to each of the successive readings of the transcripts. A high degree of reliability ( $>80 \%$ raw agreement) between the 2 coders was achieved during these successive readings. In the rare circumstance that there was a discrepancy, a third reviewer (ADN) served as a tie breaker. Using the final code key, 4 of the study authors (ADN, KRC, JC, JN) were involved in identifying study themes by noting regularities and patterns in the coded data using the process of "conclusion drawing." 24,25

\section{Results}

\section{Characteristics of the Sample}

The focus group participants $(n=45)$ averaged 44.2 years of age, and most were women $(80 \%)$. Characteristics of the study participants are de-
Table 1. Focus Group Characteristics $(n=45)$

\begin{tabular}{lc}
\hline Characteristics & Value \\
\hline Age (mean \pm SD) & $44.2 \pm 13.9$ \\
Female (n [\%]) & $36(80)$ \\
Ethnicity (n [\%]) & \\
White & $22(49)$ \\
African American & $14(31)$ \\
Hispanic & $7(16)$ \\
Asian American & $2(4)$ \\
Occupation (n [\%]) & \\
Social work & $10(22)$ \\
Physician, geriatric medicine & $8(18)$ \\
Lawyer & $6(13)$ \\
Physician, primary care & $4(9)$ \\
Nurse & $3(7)$ \\
Psychologist & $3(7)$ \\
Health educator & $3(7)$ \\
Research & $2(4)$ \\
Other & $6(13)$ \\
Professional time with vulnerable adults (\%) & \\
Social work & 52 \\
Physician, geriatric medicine & 13 \\
Lawyer & 13 \\
Physician, primary care & 13 \\
Nurse & 35 \\
Psychologist & 15 \\
Health educator & 13 \\
Research & 15 \\
Other & \\
\hline & \\
&
\end{tabular}

scribed in Table 1. Participants included 10 social workers, 12 geriatrics and primary care physicians, 6 lawyers, and a number of nurses, psychologists, and health educators.

The main findings of the focus groups are organized here by the 2 main focus group questions. Emergent themes are presented as they relate to characterizing participants' perceptions of vulnerability among older adults and their approach to screening for vulnerability. An additional section follows, presenting themes related to the screening process that are not particular to the assessment method but nonetheless are relevant to the assessment procedures.

\section{Characterizing Vulnerability among Older Adults}

Participants described vulnerability as a composite of several distinct domains. These domains were best characterized by the following 4 themes:

1. Inability to routinely perform activities of daily living. Participants described 5 broad catego- 
ries of activities consistent with safe and independent living. These activities could be broadly categorized into 5 domains: maintenance of personal finances, medical self-management, mobility, personal care and hygiene, and maintenance of a safe living environment. The focus group participants said that declines in one or more of these domains resulted in vulnerability.

2. Lack of social support. Inadequate social support was defined as a support system or safety network that was minimal, limited, or lacking. Participants included lack of knowledge or an inability to access resources as contributory factors to vulnerability: “... someone who had limited or minimal or lack of support system or a safety network. If they are physically and/or cognitively impaired, but they don't have the safety network, then they become more frail and vulnerable."

3. Social and demographic factors. Sex, ethnicity, and recent acculturation to the country were examples of factors that could contribute to vulnerability. In this context, certain socioeconomic characteristics may increase an individual's susceptibility to being exploited, misled, or victimized by others ("fraud artists or scammers"). For example, trust as a cultural characteristic, both trusting too much and distrust or fears of others, was viewed as contributing to vulnerability.

4. Neuropsychiatric conditions. Depression and dementia were identified as examples of comorbid conditions that contribute to vulnerability: "There is interplay of mental health and cognitive ability ... the loss of a spouse can decline their capabilities to deal with society ... depression leads to isolation ... which makes them vulnerable...."

These 4 themes were noted to have important interactions so that each should not be considered in isolation from the others:

"When they may decompensate because of their cognitive impairment and/or psychiatric mental problems and/or other issues in the housebold ... if they are physically and/or cognitively impaired [and] they do not have the safety network, than they become more frail and vulnerable."

"I think that the loss of some physical capabilities, small and gradual over time ... contributive to depression is probably present and leads to the isolation...."
In this regard, it was noted that vulnerability is not an either/or phenomenon but must be considered within this rich interplay of environmental factors:

"I don't see it as yes or no, but kind of a continuum ... that you could be vulnerable in some situations but not all situations, [so it's] complex."

Participants stated that vulnerability placed older adults at risk for not having the capacity for safe and independent living in the community. When asked to conceptualize capacity for safe and independent living, participants typically described 3 different types of impairments that inhibited one's capacity to make and carry out decisions related to safe and independent living. These included:

1. Cognitive deficits from dementia or other illnesses contribute to difficulty with memory, attention, and concentration. These problems contribute to patients “... leaving their cigarettes lit around the house or leaving their stove on ..."

2. Problems with reasoning and judgment that prevented vulnerable older adults from making everyday decisions. Vulnerability with these tasks included "... capacity to bandle their own activities of daily living, to manage their own financial affairs; in particular, manage their medications is a really big one to me. ..." Participants also described how problems with judgment can also expose participants to exploitation: “. . . sometimes in isolation, [impaired individuals] seem to become more vulnerable to frauds and scams, people who call on the phone, people who send them things through the mail... they're easily misled, duped, and victimized...."

3. Deficits in the performance of tasks to carryout everyday decisions. Participants described that “. . people that come to mind for me the most are the people who are highly limited in mobility, which on a day to day basis they can manage, but if they had to exit their bome quickly... [perhaps because of] a crime...their vulnerability index goes up...."

\section{Screening of Vulnerable Older Adults by Health and Social Services Professionals}

Participants described 5 components of their typical vulnerability assessment, including: 
1. Basic cognitive abilities such as memory, attention, and orientation were assessed by the usual neuropsychological screening tests like the Mini-Mental State Examination.

2. Ability to reason or judgment ("decision-making processes”). Examples provided included simple performance tests like writing a check or a clock-drawing test.

3. Personal appearance and grooming: "body odor," "urine odor," "burn holes in their clothes," and "ingrown toenails ... it's significant for self neglect."

4. Safety of the environment: "Holes in their mattress or everything with smoking"; "medication bottles and see that they are outdated or updated, that gives some idea of medical compliance"; "a cluttered bome, cluttered everywhere, trash, the kitchen is unkempt, pots, pans and dishes in the sink not being clean, just overall a dirty atmosphere"; "checkbooks all over the place or money everywhere"; "no food in the home, or spoiled food in the home."

5. Adequate and safe performance of everyday tasks. Participants felt that it was important to observe the safety and adequacy of how older adults performed in their home environment: "Ask people to get you a glass of water to see if they are able to go in the kitchen and really do that kind of task, regardless of what they report to you"; "also functional assessment, looking at the activities of daily living, their gait, ability to get out of a chair"; "vision, [when] they need to take insulin"; "if they are bedridden, not able to get up and get out."

\section{Important Considerations When Screening Vulnerability for Safe and Independent Living}

First, it was noted that the process should be comprehensive: "But also when we do house calls to see what the home environment is like and to observe the patient and/or family and whatever support system is available in terms of their appearance, in terms of their mannerisms, in terms of their level of involvement, and even with the patient ... how well they are ... cognizant of their situation."

Second, it was considered important to keep the process structured and to use validated tools to standardize measurements: "Something more standardized so everybody could be on the same pages and the same things to measure the client's ability to live independently or either to determine that the client needs placement or additional assistance."
Third, assessments should be conducted by interdisciplinary teams to ensure that the assessment is appropriately comprehensive: "Well, we work with, you know, it is an interdisciplinary team, so you bave the beauty of not only just each team member assessing them, you get to interact with them on a frequent basis...."

Fourth, the process should be practical and realistic: "I think it is better to go in with something that they have some familiarity with . . . because if you start going with something that is too abstract, it's going to get too confusing"; "Try to find a task, and a task that is real. . . and related to something that they can do because abstract thinking is so much harder than concrete thinking in terms of safety."

Fifth, the importance of assessing individuals in their own home was emphasized: "You're going to get real different scores... if you're going to use a particular tool in somebody's home where they have lived for 44 years then when they go to the [clinic or hospital] a week later."

Finally, participants emphasized the importance of conducting multiple assessments over time as opposed to single assessments: "[We] have the occupational therapist involved in the KELS [Koblman Evaluation of Living Skills] examination, so you bave a variety of testing going on ... which gives us more information ... to assess from and as we all know, that can change from, they can come in looking cognitively impaired, severely, but over time, that might even improve and change the whole assessment."

\section{Discussion}

Focus group participants described 4 key themes as distinct domains when discussing their perceptions of vulnerability among community-living older adults. These themes included the inability to perform activities of daily living, lack of social support, sociodemographic factors, and the presence of one or more cognitive or psychiatric conditions that may increase exposure to harm. Participants, who were all social services or health professionals, described screening as difficult because of the diversity of domains that comprised vulnerability. They argued that screening tools should be appropriately comprehensive to measure each domain and to capture important relationships between domains, such as the role of social support in protecting against functional decline. In addition, participants emphasized how vulnerability exists on a continuum of severity as opposed to being dichotomous. 
Whenever possible, they felt that assessments should be performed using an iterative process at several points in time.

The themes that define vulnerability are not in and of themselves novel. What was innovative were the focus groups' findings related to how social services and health professionals screened for vulnerability among older adults in community and in-home settings. These screening methods were more performance based and related to specific capacities of older adults that enabled safe and independent living in the community. Table 2 describes the 3 categories of abilities that study participants deemed instrumental in screening for vul- nerability among community-living older adults. The first category included basic cognitive abilities such as memory, attention, and orientation; the second concerned reasoning and judgment or "decision-making processes." The third can be broadly classified as the capacity to execute those decisions (executive functioning) ${ }^{26}$ relating to personal appearance and grooming, safety of the environment, and the adequate and safe performance of everyday tasks. The first column in Table 2 provides specific examples of assessments conducted by study participants as they relate to the 3 screening categories.

Participants reported that most of the time spent on screening for vulnerability is devoted to the

Table 2. Comparison of a Participant-Originated Framework for Screening Vulnerability for Safe and Independent Living Among Older Adults with Other Common Assessment Measures of Independent Living Used by Study Participants

\begin{tabular}{|c|c|c|c|}
\hline & $\begin{array}{c}\text { Study Participant-Originated } \\
\text { Framework }\end{array}$ & $\begin{array}{c}\text { Functional Independence } \\
\text { Measure }\end{array}$ & $\begin{array}{l}\text { Kohlman Evaluation of Living } \\
\text { Skills }^{30}\end{array}$ \\
\hline \multirow[t]{3}{*}{ Cognition } & 1. Memory & 1. Memory & Knowledge of: \\
\hline & 2. Attention & 2. Problem solving & 1. Emergency numbers \\
\hline & 3. Concentration & & $\begin{array}{l}\text { 2. Location of medical and } \\
\text { dental facilities }\end{array}$ \\
\hline Decision Making & $\begin{array}{l}\text { 1. Comparative reasoning } \\
\text { 2. Sequencing } \\
\text { 3. Reasoning and judgment }\end{array}$ & $\begin{array}{l}\text { 1. Audio/visual } \\
\text { Comprehension } \\
\text { 2. Verbal and nonverbal } \\
\text { expression }\end{array}$ & $\begin{array}{l}\text { Safety and Health } \\
\text { 1. Awareness of dangerous } \\
\text { household situations } \\
\text { 2. Identification of appropriate } \\
\text { action for sickness and } \\
\text { accidents }\end{array}$ \\
\hline \multicolumn{4}{|l|}{ Executive Functioning } \\
\hline \multirow[t]{7}{*}{ Maintenance of personal finances } & $\begin{array}{l}\text { Managing financial affairs i.e. } \\
\text { writing a check }\end{array}$ & NA & $\begin{array}{l}\text { 1. Use of money when } \\
\text { purchasing items }\end{array}$ \\
\hline & & & 2. Writing a check \\
\hline & & & $\begin{array}{l}\text { 3. Obtain and maintain source } \\
\text { of income }\end{array}$ \\
\hline & & & 4. Budgeting monthly income \\
\hline & & & 5. Budgeting money for food \\
\hline & & & 6. Use of banking forms \\
\hline & & & 7. Payment of bills \\
\hline Medical self-management & $\begin{array}{l}\text { Managing complex } \\
\text { medication regimen }\end{array}$ & NA & NA \\
\hline \multirow[t]{2}{*}{ Mobility } & $\begin{array}{l}\text { 1. Able to quickly exit from } \\
\text { house }\end{array}$ & $\begin{array}{l}\text { Within the house: walking, } \\
\text { wheelchair }\end{array}$ & Within the community \\
\hline & 2. Able to drive & & \\
\hline \multirow[t]{4}{*}{ Personal Care and Hygiene } & 1. Feeding & 1. Feeding & 1. Physical appearance \\
\hline & 2. Grooming & 2. Grooming & 2. Frequency of self-care \\
\hline & 3. Bathing & 3. Bathing & activities \\
\hline & 4. Dressing & 4. Dressing & \\
\hline \multirow{5}{*}{$\begin{array}{l}\text { Maintenance of a safe living } \\
\text { environment }\end{array}$} & 1. Leaving the stove on & NA & NA \\
\hline & $\begin{array}{l}\text { 2. Cigarettes left lit around } \\
\text { the house }\end{array}$ & & \\
\hline & 3. Cluttered home & & \\
\hline & 4. Fresh food available & & \\
\hline & 5. Telephone use & & \\
\hline
\end{tabular}


assessment of decision making and functional abilities, especially in areas of money and medication management, mobility, personal care, and maintenance of a safe living environment. This can be seen by the overwhelming emphasis on these 2 areas in Table 2. In contrast, outpatient clinical assessments typically focus on cognitive abilities using tools like the Mini-Mental State Examination. Clinical tools commonly used to assess functional abilities are also limited in their ability to screen for vulnerability among older adults. Some current tools for assessing vulnerability, such as the Functional Independence Measure ${ }^{27}$ and the Vulnerable Elders Scale,${ }^{28}$ typically measure functional status in a static or limited manner (see Table 2, column 2). Participants emphasized the importance of assessing the intersection of decision making and function, especially as it relates to the capacity to execute decisions (executive capacity) ${ }^{29}$ that tools like the Functional Independence Measure cannot do. Some study participants endorsed tools, such as the KELS, ${ }^{30}$ that assessed executive functioning, but these instruments cannot be used in isolation because they too leave out one or more of the critical domains described by the participants in this study (see KELS in Table 2, Column 3).

Primary care physicians who care for communityliving older adults will routinely face the increasingly common clinical question, Is my older patient vulnerable to harm and impairments that will limit his or her ability to continue to live safely and independently in his or her own home? Given the financial constraints, logistic difficulties, and complexity of assessment, primary care physicians cannot be expected to make such evaluations alone in clinical outpatient settings. Collaborations with appropriate clinical and social services professionals are critical, especially if these professionals perform routine home-based assessments of vulnerable older adults. A framework for understanding and evaluating the domains of vulnerability in community-living older adults becomes a key facilitator of communication and intervention planning among interdisciplinary teams. Furthermore, family physicians have a long tradition of performing important and specific roles that are best described as "responding to community needs." 31 The insights gathered from study participants provide the beginnings of just such a framework, which primary care physicians may use when evaluating and treating vulnerability among their older patients using information provided by in-home assessments performed by other professionals. Such a comprehensive strategy could contribute to promoting the vulnerable older person's values and preferences to the extent possible while limiting the potential for harm resulting from vulnerability. ${ }^{32}$

These findings should be considered in the light of the following limitations. Quantitative estimates of the relative importance of the various components of vulnerability were not provided, nor were the focus groups instructed to compare and contrast the strengths and weaknesses of available models for assessing vulnerability and capacity. Generalizability of results was also limited because participants were sampled from only one geographic area. However, recruitment procedures attempted to enroll a spectrum of health care and social services professionals who interacted regularly with vulnerable older adults, and participants were recruited from numerous public, private, and nonprofit organizations.

\section{Conclusions}

This study identified important gaps in current assessments and available tools for evaluating older adults' vulnerability and capacity for safe and independent living. The professionals participating in this study emphasized the (often neglected) assessment of older adults' decision making and judgment as it relates to safe and independent living. Future research is needed to develop and validate a comprehensive assessment and intervention strategy that is responsive to changes over time in vulnerability and capacity for safe and independent living that can be readily tailored for use in home environments. Furthermore, these studies should include methods for evaluating the communication and coordination of services among primary care physicians and the social services and health professionals who will implement these assessments and interventions. Continued interdisciplinary dialogue and collaboration are critical to addressing this important public health issue.

The authors would like to thank Shira Amdur and Evelyn Carlson for their assistance with participant recruitment and conducting the focus groups, and Carmel Dyer, MD, and Tziona Regev, MSW, for their insights and advice regarding the design of this study. The authors would also like to thank the Texas Elder Abuse and Mistreatment Institute, Adult Protective Services Program in the Texas Department of Family and Protective Services, Sheltering Arms Senior Services, Care for El- 
ders, Geriatrics Program at the Harris County Hospital District, Baylor Geriatric Medicine Associates, and the Harris County Department of Aging and Disability Services for their support with recruitment and ongoing participation in this scholarly work.

\section{References}

1. Cherry DK, Woodwell DA, Rechsteiner EA. National Ambulatory Medical Care Survey: 2005 summary. Adv Data 2007;(387):1-39.

2. Naik AD, Schulman-Green D, McCorkle R, Bradley $\mathrm{EH}$, Bogardus ST. Will older persons and their clinicians use a shared decision-making instrument? J Gen Intern Med 2005;20:640-3.

3. Dyer CB, Pickens S, Burnett J. Vulnerable elders: when it is no longer safe to live alone. JAMA 2007; 298:1448-50.

4. Orem D. Nursing: concepts of practice. 5th ed. St. Louis: Mosby; 1995.

5. Lauder $W$. The utility of self-care theory as a theoretical basis for self-neglect. J Adv Nurs 2001;34: 545-51.

6. McGee HM, O'Hanlon A, Barker M, et al. Vulnerable older people in the community: relationship between the Vulnerable Elders Survey and health service use. J Am Geriatr Soc 2008;56:8-15.

7. Halliday G, Banerjee S, Philpot M. Community study of people who live in squalor. Lancet 2000; 355:882-6.

8. Pavlik VN, Hyman DJ, Festa NA, Dyer, CB. Quantifying the problem of abuse and neglect in adultsanalysis of a statewide database. J Am Geriatr Soc 2001;49:45-8.

9. Lachs MS, Williams CS, O'Brien S, Pillemer KA, Charlson ME. The mortality of elder mistreatment. JAMA 1998;280:428-32.

10. Pavlou MP, Lachs MS. Could self-neglect in older adults be a geriatric syndrome? J Am Geriatr Soc 2006;54:831-42.

11. Naik AD, Burnett J, Pickens-Pace S, Dyer CB. Impairment in instrumental activities of daily living and the geriatric syndrome of self-neglect. Gerontologist 2008;48:388-93.

12. Ploeg J, Feightner J, Hutchison B, Patterson C, Sigouin C, Gauld M. Effectiveness of preventive primary care outreach interventions aimed at older people. Can Fam Physician 2005;51:1224-45.

13. Elkan R, Denise K, Dewey M, et al. Effectiveness of home based support for older people: systematic review and meta-analysis. BMJ 2001;323:1-9.

14. Moye J, Wood S, Edelstein B, et al. Clinical evidence in guardianship of older adults is inadequate: findings from a tri-state study. Gerontologist 2007;47:604-612.

15. Shievitz A, Tudiver F, Araujo A, Sanghe P, Boyle E. Do elderly people score better on cognitive tests at home? Can Fam Physician 1998;44:1652-6.

16. Naik AD, Pickens S, Burnett J, Lai JM, Dyer CB. Assessing capacity in the setting of self-neglect: de- velopment of a novel screening tool for decisionmaking capacity. J Elder Abuse Negl 2006;18:79-91.

17. Ingram CJ, O'Brien-Gonzales A, Main DS, Barley G, Westfall J. The family physician and house calls: a survey of Colorado family physicians. J Fam Pract 1999;48:62-5.

18. Laditka SB, Fischer M, Mathews KB, Sadlik JM, Warfel ME. There's no place like home: evaluating family medicine residents' training in home care. Home Health Care Serv Q 2002;21:1-17.

19. Landers SH, Gunn PW, Flocke SA, et al. Trends in house calls to Medicare beneficiaries. JAMA 2005; 294:2435-6.

20. Naik AD, Teal CR, Pavlik VN, Dyer CB, McCullough LB. Conceptual challenges and practical approaches to screening capacity for self care and protection in vulnerable older adults. J Am Geriatr Soc 2008;56:S26670.

21. Pickens S, Naik AD, Burnett J, Kelly PA, Gleason M, Dyer CB. The utility of the Kohlman evaluation of living skills test is associated with substantiated cases of elder self-neglect. J Am Acad Nurse Pract 2007;19(3):137-42.

22. Krueger RA, Casey MA. Focus groups: a practical guide for applied research. 3rd ed. Thousand Oaks, CA: Sage Publications; 2000.

23. Crabtree BF, Miller WL. Doing qualitative research. 2nd ed. Thousand Oaks, CA: Sage Publications; 2000.

24. Silverman D. Doing qualitative research: a practical handbook. Thousand Oaks, CA: Sage Publications; 2000.

25. Miles M, Huberman A. Qualitative data analysis. London: Sage Publications; 1984.

26. Skelton K, Kunik ME, Regev T, Naik AD. Determining if an older adult can make and execute decisions to live safely at home: a capacity assessment and intervention model. Arch Gerontol Geriatr 2010;50:300-5.

27. Keith RA, Granger CV, Hamilton BB, Sherwin FS. The functional independence measure: a new tool for rehabilitation. Adv Clin Rehabil 1987;1:6-18.

28. Saliba D, Elliott M, Rubenstein LZ, et al. The Vulnerable Elders Survey: a tool for identifying vulnerable older people in the community. J Am Geriatr Soc 2001;49:1691-9.

29. Naik AD, Dyer CB, Kunik ME, McCullough LB. Patient autonomy for the management of chronic conditions: a two-component re-conceptualization. Am J Bioeth 2009;9:23-30.

30. Kohlman-Thomson L. Kohlman evaluation of living skills. 3rd ed. Bethesda, MD: American Occupational Therapy Association; 1992.

31. Oandasan I, Malik R, Waters I, Lambert-Lanning A. Being community-responsive physicians. Can Fam Physician 2004;50:1004-10.

32. Coverdale J, McCullough LB, Molinari V, Workman R. Ethically justified clinical strategies for promoting geriatric assent. Int $\mathrm{J}$ Geriatr Psychiatry 2006;21:151-7. 